\title{
Microstructure and mechanical properties of Ti-6Al-4V: mill-annealed versus direct metal laser melted alloys
}

\author{
R. P. Mulay, J. A. Moore, J. N. Florando, N. R. Barton and M. Kumar \\ Lawrence Livermore National Laboratory, Livermore, California, 94550, USA \\ Corresponding author: R. P. Mulay, mulay1@llnl.gov, 925-423-0412
}

\begin{abstract}
:
Additive manufacturing processes such as direct metal laser melting (DMLM) are known to produce highly anisotropic microstructures. The present work compares the microstructure and mechanical properties of DMLM Ti-6Al-4V with that of mill-annealed alloys. Results show that the yield and hardening response of DMLM Ti-6Al-4V does not depend on the testing direction relative to the build direction, while the response of mill-annealed Ti-6Al-4V strongly depends on the testing direction. These results are discussed in light of the microstructure, texture, and polycrystal plasticity modeling.
\end{abstract}

Keywords: electron microscopy; mechanical characterization; orientation relationships; titanium alloys

\section{Introduction}

Additive manufacturing (AM) processes, such as direct metal laser melting (DMLM), offer attractive alternative methods to produce components with intricate designs such as periodic lattice structures $[1,2]$. While many applications that seek to take advantage of the AM process are focused on the tensile properties, understanding and modeling the response of lattice structures also requires knowledge of the compressive response of the material. Studies have shown that understanding the behavior of periodic structures requires knowledge of the complete stress state, including compression $[3,4]$.

DMLM has been used to process several alloys such as aluminum alloys, titanium based alloys, austenitic stainless steels, and nickel-based alloys [5,6]. In some cases, microstructures produced using DMLM have been found to be extremely anisotropic. A strong crystallographic texture and anisotropic morphology of the grains has been shown to develop in both aluminum alloys and stainless steel manufactured by DMLM $[7,8]$. The build plate serves as a heat sink causing anisotropic heat flow and the large cooling rates make it difficult to produce uniform microstructures [9, 10]. Additionally, intricate sample designs can also cause complex thermal cycles leading to non-uniform microstructures. Consequently, the microstructure and mechanical properties are anisotropic with respect to the build direction. In DMLM produced Ti-6Al-4V as well, the prior beta grains are known to develop a strong texture and columnar morphology along the build direction [11,12]. Vrancken et al. [13], have suggested that this will lead to anisotropic mechanical properties with respect to the build direction. Studies examining the tensile behavior of DMLM Ti-6Al-4V have shown differences in the ultimate tensile strength and failure strain based on the direction relative to the build. $[14,15]$. Since the tensile properties can be more susceptible to larger scale build defects, such as porosity, an understanding of whether this anisotropy extends to the compressive behavior is needed. 
Additionally, conventionally processed wrought alloys are known to develop sharp textures due to thermomechanical treatments such as rolling and forging [16,17], and the grains are elongated due to the working operations. These factors result in anisotropy in the mechanical properties. For AM materials to be placed in service, it is necessary to understand how their properties compare to the corresponding conventionally processed wrought material. While there have been several studies that have compared the results of DMLM Ti-6Al-4V to wrought material $[13,15,18]$, the focus has been on the tensile properties, and the wrought material is assumed to have isotropic properties.

The purpose of this work is to examine whether in compression, the origins of anisotropy in mill-annealed material are also exhibited in the DMLM processed AM material. The microstructure and compressive properties in DMLM Ti-6Al-4V are measured relative to the build direction and compared with mill-annealed Ti-6Al-4V. While it is known that anisotropic texture and grain morphology are connected to anisotropic response, it is unclear if the extent of the microstructural anisotropies observed in this study are sufficient to cause the observed differences in the mechanical response. A crystal plasticity-based model is used to confirm this microstructure/response connection for mill-annealed Ti-6Al-4V.

\section{Materials and Methods}

Selective laser melting was carried out using a powder bed system (Concept Laser M2) at FineLine Prototyping (Raleigh, NC) [19]. Pre-alloyed Ti-6Al-4V powder with a spherical shape and size ranging from 10-45 um was used. The process was carried out in an argon atmosphere. The sample was built on a square build plate made out of Ti-6Al-4V. The AM sample was $51 \mathrm{~mm} \times 38 \mathrm{~mm} \times 13 \mathrm{~mm}$. The build direction was along the short direction of $13 \mathrm{~mm}$. Mill annealed samples (deformed and annealed for 2 to 4 hours between 700 and $900{ }^{\circ} \mathrm{C}$ ) were obtained from a commercially purchased AMS 4911 plate, $280 \mathrm{~mm} \times 150 \mathrm{~mm} \times 7 \mathrm{~mm}$. Cylindrical compression samples $(5.1 \mathrm{~mm}$ in diameter and $5.1 \mathrm{~mm}$ length) were electro discharged machined (EDM) from the AM and mill-annealed samples in the in plane (IP) and through thickness (TT) directions (Fig.1). The through thickness direction in the AM plate corresponds to the build direction. Compression tests were carried out on an Instron $5800 \mathrm{R}$ at a nominal strain rate of $10^{-3} / \mathrm{s}$. An extensometer was attached to the platens to measure the displacement. The platens were lubricated with Apiezon $\mathrm{N}$ grease to minimize friction. Four compression tests were carried out on each of the directions for both the AM and mill-annealed samples.

In order to explain the observed mechanical behavior, microstructural analysis was performed on all the samples. Plan and cross sectional view samples (Fig.1) were prepared for back scattered imaging (BSI) and electron backscattered diffraction (EBSD) using standard metallographic procedures with a 0.05 um colloidal silica final polish. Backscattered imaging was carried out on a Philips FEG XL 30S. EBSD orientation mapping was carried out on the same instrument at an accelerating voltage of $20 \mathrm{kV}$ using a TSL acquisition system and submicron step sizes.

In order to assess the relative contributions of texture and grain morphology on the anisotropy, crystal plasticity modeling was carried out. Mechanical property predictions were performed using a finite element crystal plasticity-based model that accounts for heterogeneous 
stress and strain distributions in material microstructures including effects of grain morphology and crystallographic texture. Descriptions of such crystal mechanics based models can be found elsewhere [20,21]. The deformation kinematics were based on those used in [20] and the model accounts for plastic deformation via slip mechanisms alone. Slip kinetics were modeled using a power law $\dot{\gamma}^{\alpha}=\dot{\gamma}_{o}\left|\frac{\tau^{\alpha}}{w^{\alpha} \tau_{o}}\right|^{1 / m}$, where for a slip system $\alpha, \dot{\gamma}^{\alpha}$ is the shearing rate, $\dot{\gamma}_{o}$ is the reference shearing rate, $\tau^{\alpha}$ is the resolved shear stress, $\tau_{o}$ is the reference shear strength, and $m$ is the rate sensitivity parameter. The parameter $w^{\alpha}$ allows for preferential slip on the basal and prismatic slip modes as compared to $\langle\mathrm{c}+\mathrm{a}>$ type slip [22] and is: 1.0, 1.0, 1.13 and 3.0 for the basal, prismatic, $<\mathrm{a}>$ pyramidal, and $<\mathrm{c}+\mathrm{a}>$ pyramidal type slip respectively. Slip system strength evolution was modeled using a simplified Voce [20] hardening law $\dot{\tau}_{o}=\dot{h}_{o} \dot{\gamma}\left(\tau_{s}-\right.$ $\left.\tau_{o}\right) /\left(\tau_{s}-h_{0}\right)$ where $\dot{\gamma}=\sum_{\alpha}\left|\dot{\gamma}^{\alpha}\right|$ and $\dot{h}_{o}, \tau_{s}, h_{0}$ are material parameters given in Table 1 . The model employed 4.8 million 8-node finite elements to represent 598 grains using the ALE3D finite element code developed at Lawrence Livermore National Laboratory [23]. The mesh resolution was fine enough to resolve heterogeneous intragranular deformation as well as stress concentrations due to grain-to-grain interactions. Loading was uniaxial stress, and quasi-static in nature.

\section{Results}

The compression tests carried out on the mill-annealed and AM samples along the IP and TT directions are shown in Figure 2a. The average value of the $0.2 \%$ offset yield strength obtained is listed in Table 2, along with the variation seen from the different tests. It can be seen that both the AM samples and the mill-annealed IP sample yield at similar values. However, the initial hardening rate in the AM samples is considerably higher (Figure 2b). On comparing the stresses at $2 \%$ offset strain, where the hardening rates are more uniform across all the samples (akin to a saturation stress [24]) a larger difference ( $~ 85 \mathrm{MPa}$ ) in strength is observed between the in-plane AM and in-plane mill annealed samples. Surprisingly, both the AM samples (IP and TT) have very similar mechanical response (yield and hardening) as can be seen from Figures 2a and $2 \mathrm{~b}$, respectively. On the other hand, the IP mill-annealed sample yields at higher value ( 100 MPa higher) and has a much higher initial hardening than the TT mill-annealed sample.

Backscattered images of the plan and cross sectional views taken from the mill-annealed and AM samples are shown in Figure 3. The plan view of the mill-annealed sample shows globular $\alpha$ grains (Fig. 3a, dark contrast due to lower $\mathrm{V}$ content) with the $\beta$ phase (bright contrast due to higher $\mathrm{V}$ content) decorating the grain boundaries which is similar to the expected equilibrium microstructure in Ti-6Al-4V at room temperature [25]. Image analysis showed the volume fraction of the $\beta$ phase to be $\sim 10 \%$ by volume. The cross sectional view shows elongated $\alpha$ grains with $\beta$ again appearing along the grain boundaries (Fig. $3 b$ ). On the other hand, the AM sample mainly consists of needle shaped grains of $\alpha^{\prime}$ (Fig. 3 c and d). The cooling rate of the AM samples is very large (on the order of $10^{4} \mathrm{~K} / \mathrm{s}$ in DMLM [15]) and this results in the transformation of the $\beta$ phase into martensitic $\alpha$ '. EBSD mapping (see description below) along with fine scale TEM based orientation mapping confirmed the presence of the HCP phase $(\alpha / \alpha)$ and were unable to definitively detect the presence of any $\beta$ phase in these microstructures. Energy dispersive x-ray spectroscopy (EDS) analysis also did not show any differences in composition across the scanned area which is likely due to the fast cooling rates. However, a small amount of needles with darker contrast can also be seen (Fig. $3 \mathrm{c}$ and d) that could be $\alpha$ 
(with slightly lower $\mathrm{V}$ content) formed due to repeated heating and cooling that occurs during the DMLM process [26]. Both the plan and cross sectional views show similar needle shaped morphologies for the phases.

EBSD mapping was carried out on the mill-annealed and AM samples to determine the texture of the samples. Pole figures showing the full orientation distribution of the majority phase $\left(\alpha / \alpha^{\prime}\right)$ in the mill-annealed and AM sample are shown in Figure 4. Data from multiple scans was used to ensure sufficient sampling of grains. Intensities are plotted in terms of multiples of a uniform distribution (MUD). It can be seen that in the mill-annealed sample the normals to $\{0001\}$ crystal planes are strongly concentrated around the IP1 sample direction (Fig. 4a). The IP2 has an intermediate intensity of the $\{0001\}$ plane normal, while there is no concentration around the TT sample direction. On the other hand, in the AM sample there is a more uniform distribution of orientations with IP1, IP2 and TT not showing a strong preference for any crystallographic direction. The maximum intensity in the pole figures in the millannealed sample is high (10.5) compared to AM sample (5.9) which also indicates that a much stronger texture is present in the mill annealed sample. EBSD mapping also confirms that the majority phase is $\alpha$ or $\alpha^{\prime}$ in both materials (EBSD is unable to distinguish between $\alpha$ and $\alpha^{\prime}$ since the lattice parameters and crystal structure are very similar). Fine EBSD scans ( $0.1 \mu \mathrm{m}$ step size) are also able to identify the $\beta$ phase along $\alpha$ grain boundaries in the mill-annealed sample. But similar scans on the AM sample are not able to detect the $\beta$ phase, indicating that if retained $\beta$ phase is present in these AM samples it is only in very small quantities. If anisotropic texture and grain morphology are the primary mechanisms causing the anisotropic response of the millannealed material, then the uniformly distributed grain morphologies and uniform texture observed in the AM materials explains the isotropic mechanical properties observed in the AM samples. Also, DMLM produced materials are known to have high residual stresses [27]. These residual stresses could be responsible for the higher initial hardening rates observed in the AM samples as compared to the mill-annealed. Residual stresses are known to lower the initial yield followed by rapid initial hardening till the material approaches fully developed plastic flow. These effects are akin to the Bauschinger effect [28]. Preliminary TEM based orientation mapping also reveals a much finer scale needle microstructure in the AM materials than seen in EBSD based mapping. Further work is being carried out to understand the influence of this substructure on the hardening rate in AM materials. On the other hand, the strong texture and anisotropic grain morphologies causes a large anisotropy in the mechanical response of the millannealed materials.

To provide insight into the microstructural features that can lead to anisotropy in the mechanical response, crystal plasticity calculations of the stress strain behavior of the millannealed material are shown in Figure 2c. Since the AM material does not show differences in texture or grain morphology, the model was not applied to the AM microstructure. The influence of small amounts of retained beta phase in the mill-annealed material was neglected in the model. While this assumption may somewhat alter the stress-strain curve at initial yield, the effect is assumed to be secondary due to the low volume fraction of the beta phase and will not change the overall conclusions drawn from the model, as discussed in Picu, et al. [29]. The initial mill-annealed texture determined using EBSD (Fig. 4a) was discretized into 598 grains and used as the input texture for the model. Cylindrical shaped grain morphology with an aspect ratio of 3.7 was used for the mill-annealed material (aspect ratio measured from Fig. 3b). While there is some discrepancy in the yielding behavior between the model and experimental results, the 
model can account for the high level of anisotropy between the IP1 and TT directions seen in mill-annealed samples by incorporating effects of texture and grain morphology. The mill annealed samples were also modeled using equiaxed grains and the experimental texture (considering texture effects only) and using the observed grain morphology with a uniform texture (considering morphology effects only) (Fig. 2c). Predictions considering texture effects alone are able to capture much of the anisotropy observed in the mill-annealed samples while those considering morphology only are unable to predict the observed anisotropy. This indicates that texture rather than grain morphology is driving the observed anisotropy. Additionally the model captures the higher hardening rate observed in the mill-annealed IP sample. The texture is such that on straining along the IP direction a large number of grains are poorly oriented for slip along the basal and prismatic (soft) slip modes. As a result, these grains undergo a prolonged elastic-plastic transient that produces rapid apparent hardening after the macroscopic yield point. When the stresses are high enough to activate secondary slip modes in these grains the hardening rate reduces since all the grains are now deforming more uniformly. This initial rapid hardening has been seen in other materials with a limited number of independent slip systems [30]. These modeling results build confidence in the conclusions drawn regarding the DMLM Ti-6Al-4V response based on microstructural observations.

\section{Discussion}

Conventional Ti-6Al-4V wrought products produced by rolling or forging usually consist of a two phase $\alpha-\beta$ structure with the $\beta$ along the $\alpha$ grain boundaries as seen in the present work [24]. They are known to have directional mechanical properties due to texture and anisotropic grain morphologies. Deformation in $\alpha$-phase titanium has been studied previously and occurs both by slip and twinning [31,32]. However, increasing the Al content to levels present in Ti$6 \mathrm{Al}-4 \mathrm{~V}$ tends to suppress the occurrence of twinning in the $\alpha$-phase [32]. Prismatic and basal slip modes are considered to be the most important in $\alpha$ titanium with prismatic slip having the lower critical resolved shear stress at room temperature [33]. As a result, uniaxial deformation of a polycrystal with many crystals having their $\{0001\}$ poles near the deformation axis gives a high yield stress along with a higher initial hardening rate as the softer basal and prismatic slip modes are less easily activated. This can be seen in the case of compression along mill-annealed IP1 which produces a much higher yield stress than compression along the TT direction as there is a high density of $\{0001\}$ poles oriented along the IP1 direction.

On the other hand, previous work has reported primarily the $\alpha^{\prime}$ phase to be present in DMLM produced as-built materials [15]. During cooling in the DMLM process, the liquid metal first solidifies as the $\beta$ phase which then transforms into martensitic $\alpha^{\prime}$ due to high cooling rates. The $\beta$ phase is known to develop a strong $\{100\}$ texture at about $20^{\circ}$ to the build direction and the $\beta$ grains also have a columnar morphology along the build direction $[11,12]$. However, since the number of $\alpha^{\prime}$ variants within each prior $\beta$ grain is high (a maximum of $12 \alpha^{\prime}$ variants) the overall $\alpha^{\prime}$ texture is much more uniform than the $\beta$ phase from which it solidifies [11,12]. As a result in this work, there is a comparatively uniform crystallographic orientation distribution in the AM samples. This explains the similar mechanical properties seen in both the IP and TT directions. Examination of recent data published by Simonelii et al. [34], shows similar yield strengths for as-built tensile bars tested parallel and perpendicular to the build direction (with the same face for the specimens). This is in agreement with the present work. Carroll et al.[14], also examined the tensile properties of Ti-6Al-4V manufactured using direct energy deposition 
additive manufacturing. Their results show a difference of about $15 \mathrm{MPa}$ in yield strengths of specimens tested parallel and perpendicular to the build direction. It is interesting to note that large anisotropy in grain morphology and a strong texture is observed in DMLM produced stainless steel where no solid-state phase transformation takes place [8]. However, in DMLM produced Ti-6Al-4V, the solid-state phase transformation from $\beta$ to $\alpha^{\prime}$ leads to the formation of a more uniform microstructure with minimal anisotropy in compressive mechanical properties.

\section{Conclusions}

The anisotropy in the mechanical properties of additively manufactured Ti-6Al-4V was examined with respect to the build direction and compared to that of conventionally processed mill-annealed Ti-6Al-4V:

- The microstructure of the AM materials consists of uniformly distributed needle like grains that leads to minimal anisotropy in mechanical behavior as a function of the build direction. This is in stark contrast to the properties observed in other materials like stainless steel and aluminum alloys produced using DMLM. On the other hand, the millannealed materials show a strong texture and anisotropic grain morphologies leading to a large anisotropy in their yield strength and hardening as a function of the testing direction.

- The initial yield strength of the AM materials is comparable to the mill-annealed samples but the AM material has a higher initial hardening rate leading to a higher saturation stress in the AM materials.

- Polycrystal plasticity modeling confirms that texture and grain morphology account for the observed anisotropic response of the mill-annealed samples. The model also suggests that texture rather than grain morphology is the dominant factor in driving the anisotropy observed between the mill-annealed IP and TT samples both in yield strength and hardening rate.

\section{Acknowledgements:}

This work was performed under the auspices of the U.S. Department of Energy by Lawrence Livermore National Laboratory under Contract DE-AC52-07NA27344. The authors would like to acknowledge Dennis Freeman for carrying out the compression tests, and Jackson Go, Sharon Torres, and Edwin Sedillo for EBSD sample preparation.

\section{References:}

[1] L. E. Murr, et al., "Metal fabrication by additive manufacturing using laser and electron beam melting technologies" Journal of Materials Science \& Technology. 28(1)(2012) 1-14.

[2] A. Evans, et al., "The topological design of multifunctional cellular metals” Progress in Materials Science 46(2001)309-327. 
[3] M. Messner et al., "Wave propagation in equivalent continuums representing truss lattice materials" International Journal of Solids and Structures. 73-74(2015)55-66.

[4] J. Xiong et al., “Advanced Micro-Lattice Materials” Advanced Engineering Materials. 17(9) (2015)1253-1264.

[5] Z. Wang, et al., "The microstructure and mechanical properties of deposited-IN718 by selective laser melting" Journal of Alloys and Compounds. 513(2012)518-23.

[6] K. Kempen, et al., "Microstructure and mechanical properties of Selective Laser Melted 18Ni-300 steel" Physics Procedia. 12 (2011)255-63.

[7] L. Thijs, et al., "Fine-structured aluminium products with controllable texture by selective laser melting of prealloyed AlSi10Mg powder" Acta Materialia.61(5) (2013)1809-19.

[8] T. Niendorf, et al., "Highly anisotropic steel processed by selective laser melting" Metallurgical and Materials Transactions B. 44(4) (2013)794-6.

[9] L. Thijs, et al., "A study of the microstructural evolution during selective laser melting of Ti-6Al-4V" Acta Materialia. 58(9)(2010) 3303-12.

[10] T. Vilaro, et al., "Direct fabrication of a Ti-47Al-2Cr-2Nb alloy by selective laser melting and direct metal deposition processes" Advanced Materials Research. 89 (2010)586-91.

[11]M. Simonelli, Y.Y. Tse, C. Tuck, Further Understanding of Ti6Al4V Selective Laser Melting Using Texture Analysis. in Proceedings of 23rd Annual International Solid Freeform Fabrication Symposium, Austin, TX., 2012, pp.480

[12] M. Simonelli, Y. Y. Tse, C. Tuck, "On the texture formation of selective laser melted Ti-6Al-4V" Metallurgical and Materials Transactions A. 45(6) (2014) 2863-72.

[13] B. Vrancken, et al., "Heat treatment of Ti6Al4V produced by selective laser melting: microstructure and mechanical properties" Journal of Alloys and Compounds. 541 (2012) 177-85.

[14] B. E. Carroll, T. A. Palmer, A. M. Beese, "Anisotropic tensile behavior of Ti-6Al-4V components fabricated with directed energy deposition additive manufacturing”Acta Materialia. 87 (2015)309-20.

[15] T. Vilaro, C. Colin, J.D. Bartout, "As-fabricated and heat-treated microstructures of the Ti-6Al-4V alloy processed by selective laser melting" Metallurgical and Materials Transactions A. 42A (2011) 3190-9.

[16] S. L. Semiatin, V. Seetharaman, I.Weiss, "The thermomechanical processing of alpha/beta titanium alloys" JOM. 49(6) (1997) 33-9.

[17] W. C. Liu, J. G. Morris, "Quantitative analysis of texture evolution in cold-rolled, continuous-cast AA 5xxxseries aluminum alloys" Metallurgical and Materials Transactions A. 35(1) (2004)265-77.

[18] H. K. Rafi et al., "Microstructures and mechanical properties of Ti6Al4V parts fabricated by selective laser melting and electron beam melting" Journal of Materials Engineering and Performance 22(12)(2013)3872-3883.

[19] http://www.protolabs.com/additive-manufacturing/direct-metal-laser-sintering/

[20] N. Barton, P. Dawson, M. Miller, "Yield strength asymmetry predictions from polycrystal

elastoplasticity" Journal of Engineering Materials and Technology. 121(2) (1999) 230-9.

[21] N. R. Barton, N. W. Winter, J. E. Reaugh, "Defect evolution and pore collapse in crystalline energetic materials" Modelling and Simulation in Materials Science and Engineering. 17.3 (2009) 035003.

[22] J. R. Mayeur, D. L. McDowell, "A three-dimensional crystal plasticity model for duplex Ti-6Al-

4V" International journal of plasticity. 23(9) (2007)1457-85.

[23] A Anderson, et al., "Users manual for ALE3D — an arbitrary Lagrange/Eulerian 3D code system” ,

Lawrence Livermore National Laboratory. UCRL-MA-152204(2003).

[24] U. F. Kocks, "Laws for work-hardening and low-temperature creep" Journal of engineering materials and technology. 98(1) (1976)76-85.

[25] R. Pederson, Microstrcture and Phase Transformation of Ti-6Al-4V, Lulea University of Technology thesis, 2002, pp. 10-14.

[26] M. Simonelli, Y. Y. Tse, C. Tuck, "Microstructure of Ti-6Al-4V produced by selective laser melting" Journal of Physics: Conference Series. 371(2012) 012084.

[27] P. Mercelis, J. Kruth, "Residual stresses in selective laser sintering and selective laser melting" Rapid Prototyping Journal. 12(5) (2006)254-65.

[28] J. Bauschinger, "On the Change of the Elastic Limit and Hardness of Iron and Steels through Extension and Compression, through Heating and Cooling, and through Cycling" Mitt. Mech.-Tech. Laboratorium K. Technischen Hochschule Munchen.13 (5)(1886)31.

[29] R. C. Picu, and A. Majorell, "Mechanical behavior of Ti-6Al-4V at high and moderate temperatures-Part II: constitutive modeling" Materials Science and Engineering A. 326(2) (2002)306-16. 
[30] J. A. Wollmershauser, C. J. Neil, S. R. Agnew, "Mechanisms of ductility in CoTi and CoZr B2 intermetallics" Metallurgical and Materials Transactions A. 41.5 (2010)121729.

[31] A.T. Churchman, "The slip modes of titanium and the effect of purity on their occurrence during tensile deformation of single crystals" Proceedings of Royal Socitey. A226 (1954) 216-26.

[32] F. D. Rosi, F. C. Perkins, L.L. Seigle, "Mechanism of plastic flow in titanium-determination of slip and twinning elements" Trans. AIME.197 (1953) 257.

[33] N.E. Paton, J.C. Williams, G.P. Rauscher, The Deformation of alpha phase titanium, in: R.I. Jaffee, H.M. Burte (Eds.), Titanium Science and Technology, New York-London, 1973, pp. 1049-70.

[34] M. Simonelli, Y. Y. Tse, C. Tuck, "Effect of the build orientation on the Mechanical Properties and Fracture Modes of SLM Ti-6Al-4V" Materials Science and Engineering: A. 616 (2014) 1-11. 


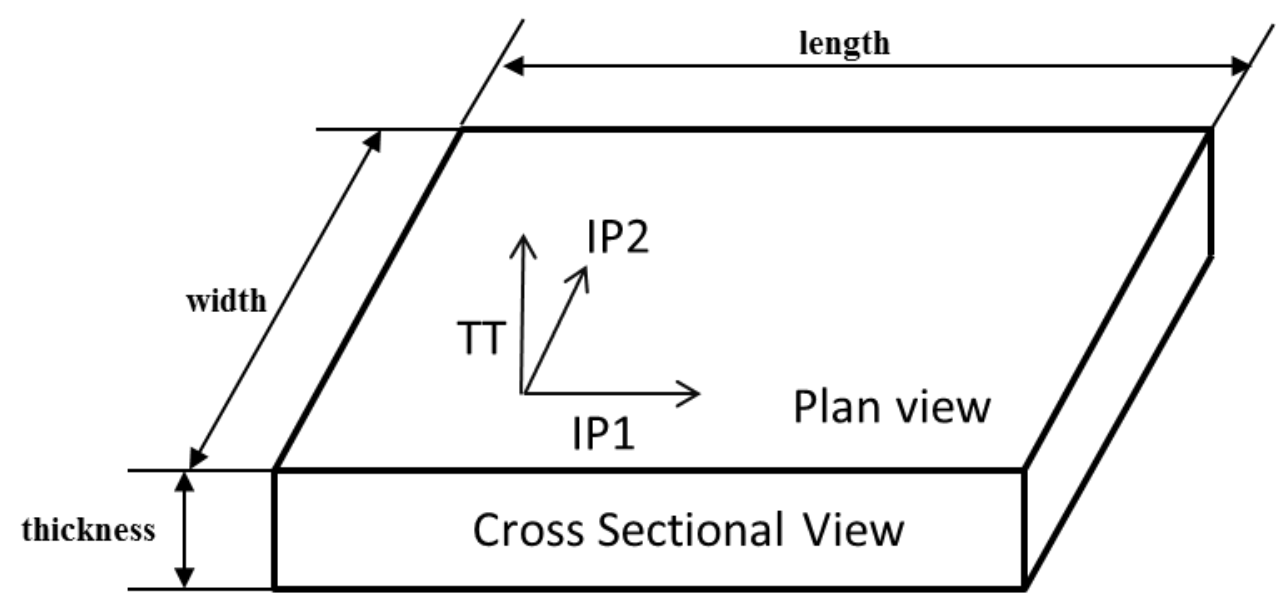

Figure 1: Schematic showing the in plane (IP1 and IP2) and through thickness directions (TT), plan and cross sectional views (PV and CS), in both the mill-annealed and AM samples. 

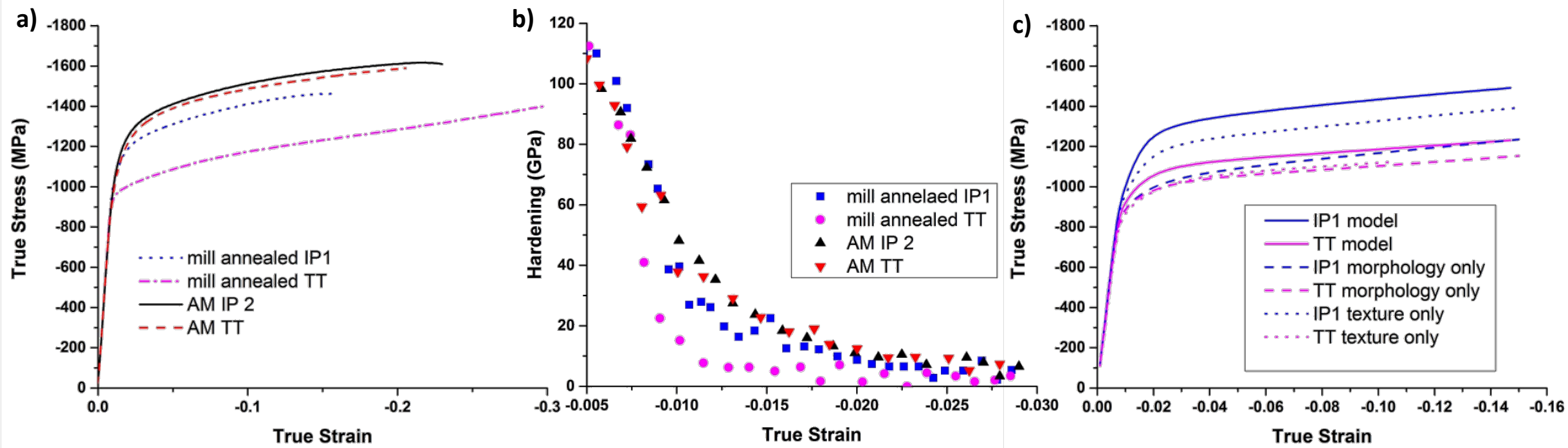

Figure 2: a) Experimentally determined compressive stress strain curves obtained from the mill annealed and AM samples in different testing directions b) corresponding hardening as a function of strain and c) model predictions of the mill-annealed sample showing effects of considering texture vs morphology. 
a)

c)

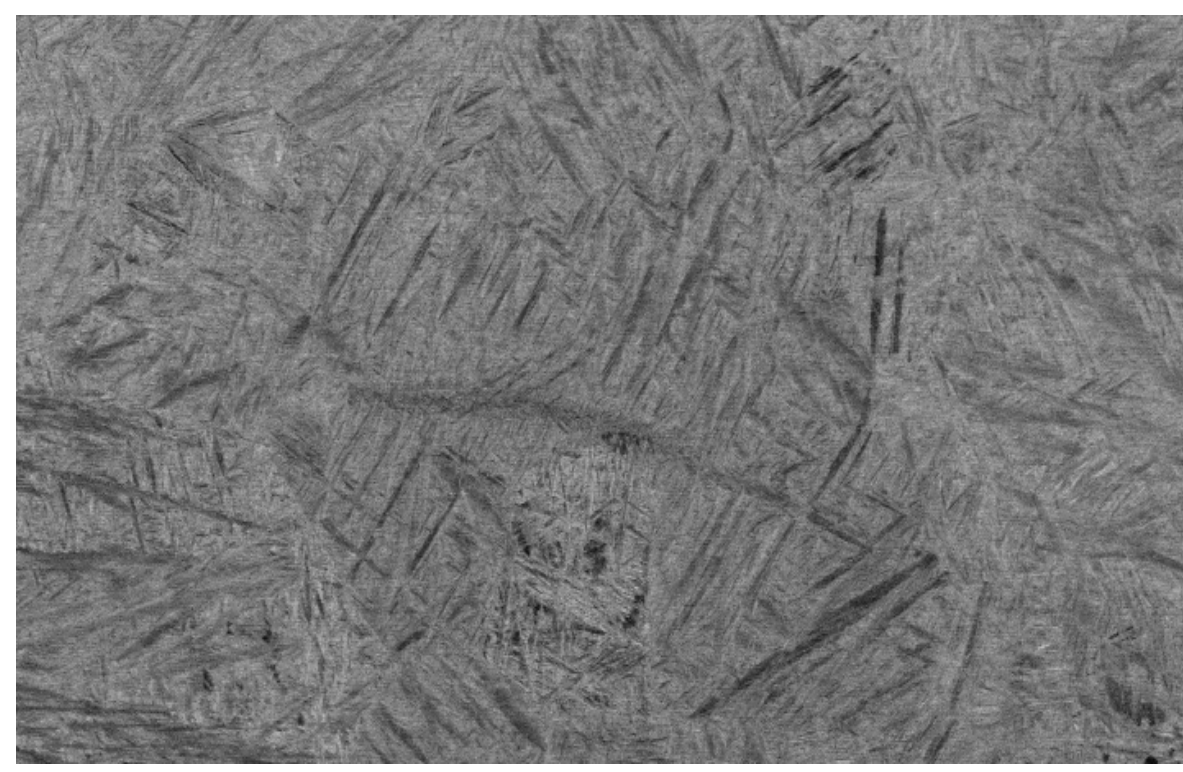

b)

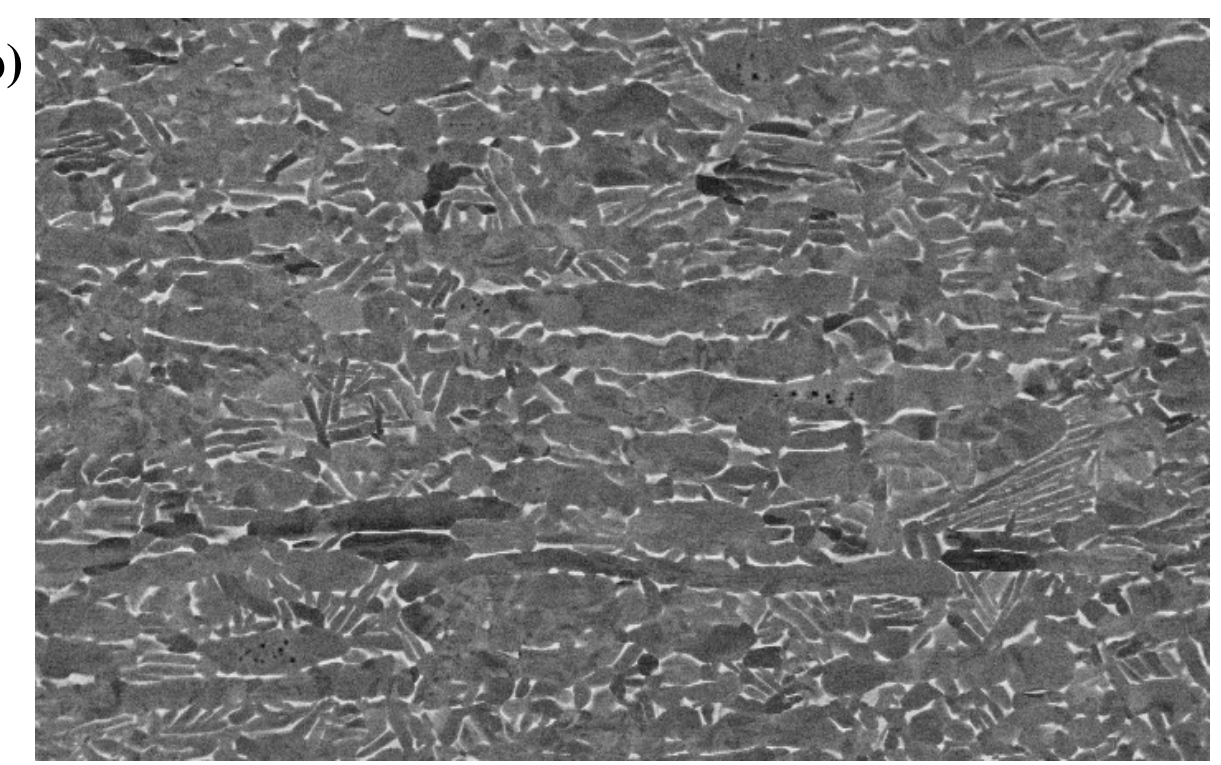

d)

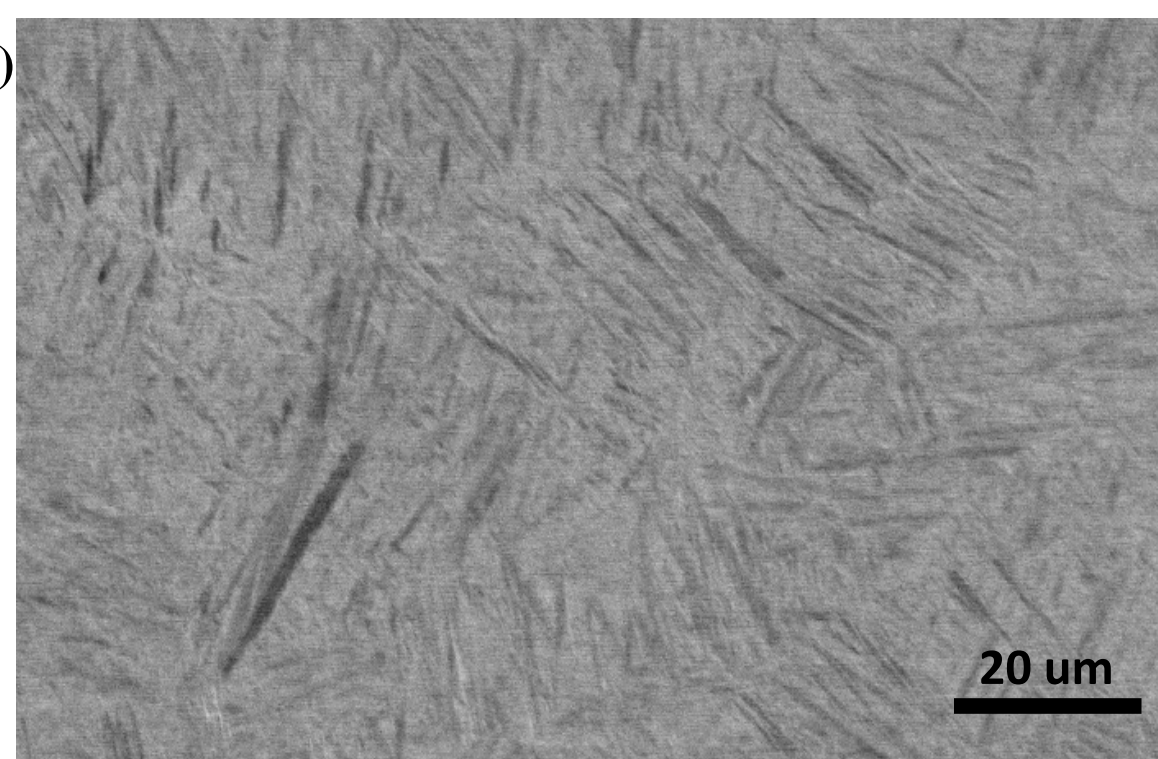

Figure 3: SEM backscattered images of the mill annealed sample a) plan view, b) cross sectional view, and AM sample c) plan view, d) cross sectional view. 
a)
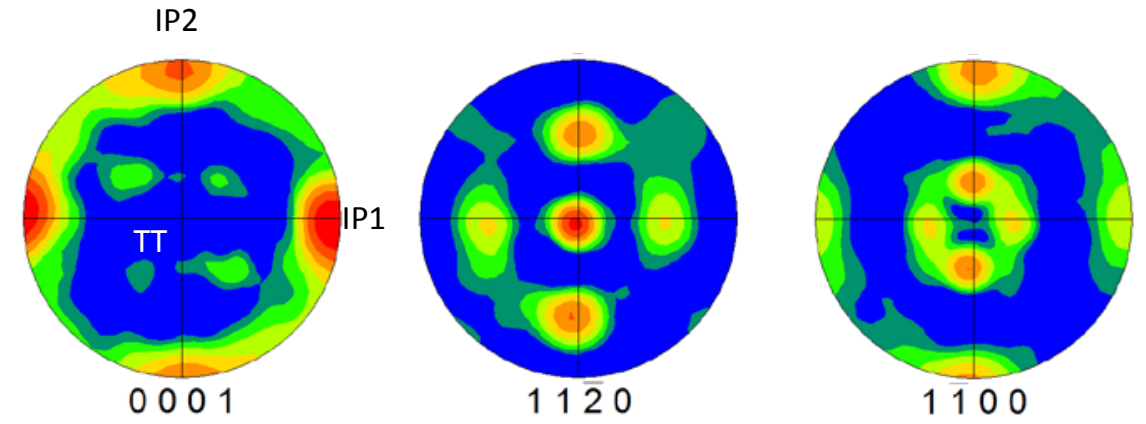

Max intensity $=10.455$

b)
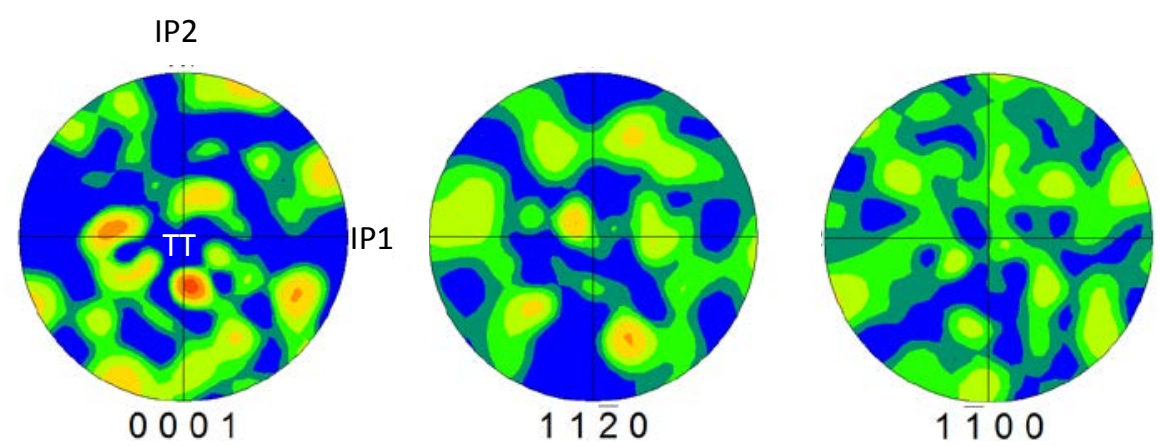

Multiples of uniform distribution (mud)

Figure 4: Pole figures showing the orientations of the HCP phase in the a) mill-annealed and b) AM materials 
Table 1: Crystal plasticity model parameters

\begin{tabular}{|c|c|c|c|c|c|c|c|c|c|c|}
\hline \multicolumn{2}{|c|}{ Kinetics } & \multicolumn{4}{c|}{ Hardening, MPa } & \multicolumn{5}{c|}{ Elastic Moduli, GPa } \\
\hline$\dot{\gamma}_{o}(1 / \mathrm{sec})$ & $m$ & $\dot{h}_{o}$ & $\tau_{s}$ & $h_{0}$ & $\tau_{o}^{\alpha}$ (initial) & $C_{11}$ & $C_{12}$ & $C_{13}$ & $C_{33}$ & $C_{44}$ \\
\hline 1 & 0.05 & 90 & 1517 & 350 & 350 & 162.4 & 92.0 & 69.0 & 180.7 & 46.7 \\
\hline
\end{tabular}

Table 2: Compressive strengths obtained in the Ti-6Al-4V samples

\begin{tabular}{|c|c|c|}
\hline Sample & $\begin{array}{c}\text { Yield Strength (MPa) (0.2 \% } \\
\text { offset) }\end{array}$ & $\begin{array}{c}\text { Flow Strength at 2\% } \\
\text { offset (MPa) }\end{array}$ \\
\hline mill-annealed IP1 & $1059 \pm 3$ & $1262 \pm 6$ \\
\hline mill-annealed TT & $954 \pm 3$ & $1041 \pm 15$ \\
\hline AM IP2 & $1066 \pm 13$ & $1344 \pm 10$ \\
\hline AM TT & $1025 \pm 9$ & $1340 \pm 3$ \\
\hline
\end{tabular}

